\title{
El policial del desencanto: una lectura generacional de Máscaras, de Leonardo Padura
}

\author{
MARIO GutiÉRREZ BLANCA \\ Universidad Autónoma de Madrid \\ mario.gutierrezb@estudiante.uam.es
}

Resumen: Este artículo analiza Máscaras, de Leonardo Padura, desde un prisma generacional. En primer lugar, se caracterizará de la novela neopolicial de Padura a partir de la revisión de las coordenadas históricas y literarias del paradigma que lo precede y contra el que nace: la novela policiaca revolucionaria, que tuvo su auge en la Cuba de los setenta. En segundo lugar, nos detendremos en el origen, características y transformaciones del personaje protagonista Mario Conde. Finalmente, se explorará la estrecha relación que une a Conde y a otros personajes con la experiencia biográfica de Padura para observar cómo se proyecta en Máscaras una mirada generacional sobre el presente cubano.

Palabras clave: literatura cubana, novela policial, Leonardo Padura, Periodo Especial.

The crime fiction of disenchantment: a generational approach to Máscaras by Leonardo Padura

Abstract: This article analyses Máscaras by Leonardo Padura from a generational point of view. Padura's neo-crime fiction arose in reponse to the revolutionary crime fiction, which had its apogee in Cuba in the 1970s. For this reason, we will start by characterizing the historical and literary circumstances of this paradigm. Secondly, we will explore the origin, characteristics and evolution of the main character Mario Conde. The relationship that unites Conde and other characters with Padura's biographical experience is very close. By analysing this relationship, we will observe how a generational view of the Cuban present is projected in Máscaras.

Keywords: Cuban literature, crime fiction, Leonardo Padura, Special Period. 


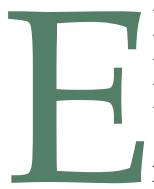
l éxito del ciclo de novelas policíacas protagonizadas por el teniente Mario Conde le ha proporcionado al escritor y periodista cubano Leonardo Padura Fuentes (La Habana, 1955) el reconocimiento a nivel internacional. Máscaras (1995) es la tercera de las novelas que componen la tetralogía titulada Las cuatro estaciones y, junto a Pasado perfecto (1991), Vientos de Cuaresma (1994) y Paisaje de Otoño (1998), constituye una cartografía de las problemáticas y sentimientos que circulaban en la sociedad cubana de 1989. Esta fecha es decisiva, a nivel global, porque en noviembre de aquel año se produjo la caída del Muro de Berlín y el comienzo de la desintegración de la Unión Soviética; y a nivel local, porque el colapso del bloque socialista traería consigo la más grave crisis económica vivida hasta entonces en Cuba, el llamado Periodo Especial. Pero además, como dice Padura en una entrevista,

[...] es el año de los fusilamientos de Ochoa y La Guardia, de las revelaciones de los vínculos con el narcotráfico, donde yo, como individuo, y creo que la sociedad cubana en gran proporción, pierde muchas esperanzas. Por primera vez el descreimiento se hace general (Epple, 1995: 58).

Según Uriel Quesada, por el momento de escritura, por los temas tratados y por el aire de decepción y pérdida que la recorre, Las cuatro estaciones puede considerarse una «obra histórica catártica, crítica sobre ciertas contradicciones del proyecto revolucionario cubano, que han condicionado el presente y las perspectivas de futuro de la generación nacida en los años cincuenta» (2016: 3).

\section{De la novela policiaca revolucionaria a la novela neopolicial de Padura}

El trabajo en Máscaras y las otras novelas de la tetralogía con los códigos de la novela policial hace necesario partir del examen de la peculiar situación que vivía el género en Cuba. En un ensayo titulado «Modernidad y posmodernidad: La novela policial en Iberoamérica», Padura traza un recorrido por la historia del policial escrito en lengua española y se detiene en el análisis de la llamada «novela policiaca revolucionaria», que experimentó su mayor auge entre las décadas de los setenta y ochenta. Como sostiene Padura, el hecho de que esta literatura fuese escrita en un país socialista bajo el amparo y financiación del Ministerio del Interior basta para singularizarla dentro del 
ámbito hispanoamericano (1999: 46). Con esto, Padura se refiere a la creación, en 1972, por parte de este ministerio, del concurso de literatura policial «Aniversario del Triunfo de la Revolución», una muestra del cambio en las políticas culturales del gobierno a raíz de los debates surgidos en torno al polémico caso Padilla ${ }^{1}$. El Congreso de Educación y Cultura celebrado en 1971 fijó una serie de normas estéticas, e incluso de comportamiento, que trajeron consigo la exclusión de muchos intelectuales del panorama cultural por razones ideológicas o relativas a su orientación sexual a través del procedimiento denominado «parametración». Se trató de la puesta en marcha de las medidas que ya se anunciaban en el Congreso:

Se sugirió el estudio para su aplicación de medidas que permitan la ubicación en otros organismos de aquellos que siendo homosexuales no deben tener relación directa en la formación de nuestra juventud desde una actividad artística o cultural (en Padura, 1999: 47).

La mayoría de las víctimas de la parametración fueron docentes y trabajadores del mundo del teatro: dramaturgos, actores e incluso técnicos. Aquellos que no respondían a las exigencias o «parámetros» que los calificaran como individuos confiables - es decir, revolucionarios y heterosexuales fueron reubicados en otros centros de trabajo (Fornet, 2007: 16). La representación de estos procesos de depuración en Máscaras se lleva a cabo a través de la figura de Alberto Marqués, dramaturgo homosexual condenado al ostracismo en los años setenta. Así lo describe el propio personaje:

Mire, hace dieciocho años, cuando corría el año del Señor de 1971, yo fui parametrado y, claro, no tenía ningún parámetro de los que se pedían. Se imagina eso, ¿parametrar a un artista, como si fuera un perro con pedigrí? Casi que es cómico, si no hubiera sido trágico. Y, de contra, es una palabra tan feísima... Parametrar. Bueno, empezó toda aquella historia de la parametración de los artistas y me sacaron del grupo de teatro y de la asociación de teatristas, y después de comprobar que no podía trabajar en una fábrica, como debía ser si quería purificarme con el contacto de la clase obrera, aunque nadie me preguntó nunca si yo deseaba ser puro ni a la clase obrera si estaba dispuesta a cometer tal empeño desintoxicante, pues me pusieron a trabajar en una biblioteca pequeñita que está en Marianao, clasificando libros (Padura, 1997: 54-55).

1 Una aproximación a las discusiones surgidas a partir de la detención y autocrítica del poeta Heberto Padilla puede consultarse en Gilman (2003: 233-264). 
El destino de Marqués es asimilable al del principal referente real que manejó Padura para su construcción. Virgilio Piñera es homenajeado reiteradamente en la novela y su nombre es uno de los que Padura menciona entre los escritores que fueron alejados de la actividad intelectual y condenados al olvido, al ver sus obras fuera de circulación durante casi diez años: «José Lezama Lima², Virgilio Piñera, Pablo Armando Fernández, Jesús Díaz, Antón Arrufat, Norberto Fuentes, Miguel Barnet y Eduardo Heras León, entre los más notables» (1999: 47).

Esta ruptura en el campo cultural cubano produjo un vacío que «en algunos casos se trató de llenar de forma artificial con la promoción de nuevas figuras que sustituyeran a las excluidas» (Padura, 1999: 47). De esta manera, no resulta extraño que la popularización del modelo de la novela policiaca revolucionaria coincida con los años conocidos como el «Quinquenio Gris», término acuñado por Ambrosio Fornet para denominar este nefasto periodo para la cultura cubana (Epple, 1995: 50). Escritas bajo el auspicio de las nuevas políticas culturales del gobierno, las novelas policiacas revolucionarias estaban construidas de acuerdo con los preceptos estéticos de un realismo socialista que, según Padura, «tenía mucho de socialista pero poco de realismo» (1999: 48). Se trataba de novelas muy esquemáticas donde los personajes y situaciones respondían a lógicas maniqueas: «de un lado los órganos cubanos de investigación policial o de seguridad del Estado, y del otro la delincuencia contrarrevolucionaria o los agentes de la CIA -la encarnación del imperialismo y del mal» (1999: 48). Los informes sobre Alberto Marqués con los que Conde enfrenta el primer interrogatorio de Máscaras constituyen una evidente parodia de estas novelas:

[...] cualquier cosa era posible tratándose de aquel preciso y diabólico Alberto Marqués: homosexual de vasta experiencia depredadora, apático político y desviado ideológico, ser conflictivo y provocador, extranjerizante, hermético, culterano, posible consumidor de marihuana y otras drogas, protector de maricones descarriados, hombre de dudosa filiación filosófica, lleno de prejuicios pequeñoburgueses y clasistas, anotados y clasifica-

2 Sobre el caso específico de Lezama Lima se pronuncia Padura en una entrevista. En Cuba nunca estuvo prohibido leer a Lezama: «Pero en la realidad sí, porque se hizo una sola edición de su libro capital, Paradiso, que realizó la Unión de Escritores en 1966, que no pasó de mil ejemplares, sin que se haya reeditado sino hasta finales de la década de los ochenta. Es decir, leer a Lezama era un prodigio de empeño: había que hacer esfuerzos inauditos» (Epple 1995: 53) 
dos con la indudable ayuda de un moscovita manual de técnicas y procedimientos del realismo socialista... (Padura, 1997: 41)

En lugar de tomar como referencia el modelo norteamericano - mucho más crítico, duro, ligado a un manejo de la realidad que Ricardo Piglia llama materialista (2001: 61) - , los autores cubanos del género trabajaron sobre los esquemas mucho más conservadores de la novela de enigma, que se amoldaban mejor a los intereses ideológicos del gobierno. Así lo explica Néstor Ponce en relación con las novelas de Padura:

Le roman policier de la révolution, comme le roman d'énigme du XIXe siècle, insistait sur la situation d'équilibre sociale avant le délit. L'image d'équilibre était « naturalisée » et cette représentation s'imposait ainsi à la réalité. Or, chez Padura, le point de départ est le désordre, le manque $\mathrm{d}^{\prime}$ harmonie, un paysage social où rien n'est stable (2010: 2)

En efecto, «si los presupuestos del policial en las dos décadas precedentes apuntaban a la certidumbre y la confianza en los organismos del Estado, las novelas de Padura señalan la incertidumbre y el desencanto» (Rosell, 2000: 450). En el caso de Máscaras, el primero de estos términos remite la sensación que subyace al concepto que atraviesa la novela desde el mismo título (Wilkinson, 2006: 132). El asesinato que desencadena la investigación es el de un travesti asfixiado a manos de su padre, un alto diplomático que temía que su hijo hiciese pública su condición de falso revolucionario. Cae la máscara, se resuelve el crimen y sale a la luz un pasado marcado por la corrupción y el oportunismo, con la falsificación en 1959 de documentos que atribuían al diplomático todo un historial de lucha clandestina contra el dictador Fulgencio Batista. Como señala Clemens A. Franken, que el criminal de la novela pertenezca a la cúpula política cubana es algo insólito (2006: 128). Junto a esa máscara, caen otras: la del capitán Gordo Contreras, al descubrirse que ha incurrido en delitos de corrupción; la de la Maruchi, al saberse que era una infiltrada de Investigaciones Internas; la del Otro Muchacho, al mostrarse como delator de escritores; e incluso la del propio Conde, al revelarse que tras la cara de policía que lo había obsesionado desde el principio de la novela se escondía el rostro de un verdadero escritor. Los alcances críticos de la investigación - pero sobre todo de la imagen de la sociedad cubana que la rodea - hacen de Máscaras una obra inimaginable en el marco de la política cultural de los setenta. En palabras de Padura, se trata de «una novela de 
homosexuales, de máscaras, centrada en ese fenómeno de travestismo moral que se ha vivido en Cuba en este tiempo, en que las personas dicen algo y piensan otra cosa, obligadas por las circunstancias» (Epple, 1995: 58). Pero también se puede leer a través de la descripción que Alberto Marqués hace de su proyecto de montaje de la Electra Garrigó de Piñera, una historia donde la máscara facial debía ayudar a revelar la máscara moral con la que vivía mucha gente en Cuba:

[...] homosexuales que aparentan no serlo, resentidos que sonríen al mal tiempo, brujeros con manuales de marxismo bajo el brazo, oportunistas feroces vestidos de mansos corderos, apáticos ideólogos con un utilísimo carnet en el bolsillo: en fin, el más abigarrado carnaval en un país que muchas veces ha debido renunciar a sus carnavales... (Padura, 1997: 166)

Por otra parte, la profundidad psicológica de personajes como Mario Conde no hubiera sido posible si el policial de Padura no hubiera nacido opuesto al modelo revolucionario, totalmente agotado ya en los años noventa. En aquellas novelas, la figura del «héroe» la ocupaba a menudo un sujeto colectivo que respondía «más a la realidad de los reglamentos policiacos que a las necesidades dramáticas de la realidad novelesca, más al discurso político oficial que a la creación de conflictos humanos» (Padura, 1999: 48). La individualidad que exhibe el protagonista de Máscaras engarza en cambio con un tipo de novela de ámbito iberoamericano que toma el nombre de «neopolicial $»^{3}$, cuyas características resume el propio Padura: disminución del enigma como elemento dramático fundamental, preferencia por los ambientes marginales, uso de determinadas formas de la cultura popular, empleo de un lenguaje literario pero a la vez irreverente y sobre todo la renuncia a la creación de grandes héroes: «Los policías, investigadores, detectives, como se les llame, son por lo general gente frustrada, jodida, y no tienen nada de triunfadores» (Epple, 1995: 60).

En el campo literario cubano, la producción de Padura se inscribe en una generación de escritores que despliega un discurso mucho más crítico respecto de la realidad de la isla (Redruello, 2010: 124). Padura describe los textos producidos a partir de esta década como una literatura crítica con el

\footnotetext{
3 Para una revisión de los orígenes del término y un panorama de la novela neopolicial latinoamericana en que se inscribe la producción de Padura, véase el artículo de Javier Sánchez Zapatero y Àlex Martín Escribà «Revolución, desencanto y crítica: la novela criminal cubana» (2014).
} 
presente, con los comportamientos humanos y los procesos sociales ocurridos en el país, que revisa determinados asuntos históricos pero sobre todo explora la difícil cotidianeidad cubana (Epple, 1995: 51-52). De este contexto creativo surge Máscaras; de sus limitaciones, pero también de su horizonte de posibilidad. Así lo expresa Padura:

Como nunca antes, en ningún momento revolucionario, el escritor se ha sentido más libre e independiente. La misma crisis económica que se está padeciendo, la imposibilidad del Estado de seguir actuando de mecenas omnipresente, habiendo ejercido esta función por muchos años (y la ejerció en general de una manera positiva, excepto durante esos años esquemáticos y dogmáticos de los setenta), al desaparecer ese compromiso del Estado con el escritor, cambian también las relaciones de compromiso del escritor con el Estado. En este nuevo contexto de relaciones el escritor se siente mucho más libre para expresarse y analizar la realidad, y con una perspectiva mucho más abierta al pensamiento crítico (Epple, 1995: 52)

\section{Nacimiento y avatares de un falso policía}

Padura sitúa la creación de Mario Conde en los últimos días de 1989 (2019: 115). Hasta entonces, la política social cubana había logrado grandes avances en educación, salud, seguridad social, empleo y distribución de la riqueza gracias las prioridades del gobierno, la ayuda de 65000 millones de dólares otorgada por la Unión Soviética desde los años sesenta y el apoyo comercial del resto de países del Consejo de Ayuda Mutua Económica (CAME) (Mesa-Lago, 2005: 184). Pero la caída del Muro de Berlín y el colapso del campo socialista supusieron un golpe durísimo para la economía cubana. Después de la recesión que había causado el giro antimercado del proceso de Rectificación (1986-1990), la desintegración de la Unión Soviética, la persistencia del bloqueo estadounidense - que Mesa-Lago deja fuera del diagnóstico-, «así como la incapacidad del modelo cubano para generar crecimiento económico sostenible, expandir y diversificar las exportaciones y lograr una sustitución de importaciones, provocaron una severa crisis que tocó fondo en 1993» (Mesa-Lago, 2005: 184). La década de los noventa en Cuba fueron años de carencias y dificultades que se conocieron bajo el nombre oficial de Periodo Especial en Tiempo de Paz. Según Padura, se trata de un eufemismo para designar un momento dramático y revelador en que los cubanos 
sufrieron las consecuencias de la incapacidad nacional para valerse económicamente por sí mismos. A lo largo de esta década, la escasez de comida, dinero, electricidad, transporte público, papel, medicinas y otros recursos se acompañó de una degradación de la situación social (Padura, 2019: 70). En Cuba, «el año que cambió el mundo» fue el gozne entre dos países. 1989 fue un puente entre dos épocas.

El verano de calor asfixiante que invade el umbral de Máscaras fue además testigo de dos históricos procesos judiciales en la isla: las causas 1 y 2/89. La primera fue el juicio por el caso Ochoa-La Guardia, en julio, que terminó con la ejecución de varios altos mandos del ejército y del Ministerio del Interior por cargos de corrupción, narcotráfico y traición a la patria (Padura, 2019: 116-117). Un mes más tarde, el ex ministro del Interior José Abrantes - que había sido destituido en el marco de la misma investigación - , fue condenado a veinte años de cárcel por abuso de cargo, negligencia en el servicio, uso indebido de recursos financieros y ocultación de información ${ }^{4}$. Según Padura, aquellos juicios sirvieron a muchos para comprobar las dimensiones y profundidad de la grieta que atravesaba la aparentemente monolítica estructura política, militar e ideológica cubana (1999: 117). Fueron los primeros indicios para emprender la tarea de «entender mejor el mundo cercano y el lejano, comenzar a releer la historia y sus mitos, a reevaluar nuestra experiencia personal, generacional, nacional» (Padura, 2019: 71).

En las últimas semanas de 1989, Padura empezó a escribir los primeros párrafos de Pasado perfecto y a dar vida así a un personaje que excederá los límites de Las cuatro estaciones ${ }^{5}$. Como ha explicado el escritor en varias ocasiones, si Mario Conde nació policía, y no detective, fue solamente por razones de verosimilitud, ya que en Cuba un investigador por cuenta propia no puede perseguir delitos de sangre. Pero Conde es un policía atípico; o como dice su autor: un antipolicía que ingresó en el cuerpo «únicamente porque no le gusta que los hijos de puta puedan hacer las cosas impunemente» (Epple, 1999: 57). Le gusta el alcohol y se demora poco en terminar las copas - como bien sabe Poly: «Dios, qué horror, cómo tragas» (Padura, 1997: 141) - : bote-

4 El País, «José Abrantes Fernández, ex ministro del Interior cubano», 23 de enero de 1991. En línea: https:/ / elpais.com/diario/1991/01/23/agenda/664585202_850215.html Último acceso el 10-mar-2020.

5 Además de en la tetralogía policíaca, el personaje de Mario Conde aparece en algunas de las producciones posteriores del escritor cubano: La cola de la serpiente (2001), Adiós Hemingway (2001), La neblina del ayer (2005), Herejes (2013) y La transparencia del tiempo (2018). 
llas de ron o cerveza que casi siempre toma junto a sus amigos, un círculo reducido que conserva desde hace años y al que guarda una fidelidad absoluta. Conde es además nostálgico, inteligente, irónico, tierno, enamoradizo, sin asideros ni ambiciones materiales «y, por encima de todo, un hombre honrado, una persona "decente", como suele decirse en Cuba, con una ética flexible pero inamovible en los conceptos esenciales» (Padura, 2019: 122).

Todas estas características contribuyen a la humanización de un personaje por lo demás solo verosímil en los márgenes de la ficción narrativa, impensable dentro de la policía real cubana o de cualquier otra institución que exija una disciplina férrea (Padura, 2019: 121). La contradicción más profunda que arrastra Conde es el hecho de ser un policía-escritor o un escritor-policía. Sus investigaciones están impregnadas de literatura porque piensa como un escritor, de ahí la persistencia en la lectura intertextual entre el Evangelio y la obra teatral de Piñera, por ejemplo; o los peculiares interrogatorios en casa de Alberto Marqués, de los que excluye a Manolo, su compañero - que sí es un verdadero policía - , consciente de que los métodos que emplea se alejan mucho de la ortodoxia del oficio. El sistemático olvido del arma reglamentaria (Padura, 1997: 16, 28, 135) y la obsesión por haber desarrollado cara de policía muestran la insatisfacción de Conde con respecto a su trabajo, un malestar que se agudiza a lo largo de Máscaras y se resolverá en la última entrega de la tetralogía, Paisaje de otoño, cuando Conde abandone definitivamente el cuerpo de policía para dedicarse a la escritura literaria.

Cabe destacar que las dos mayores transformaciones que experimenta Conde a lo largo de la novela las cataliza la figura de Alberto Marqués. De un lado, el paso del no-saber al saber - un elemento clásico de la literatura policiaca - no se limita en Máscaras al esquema de la investigación pura y a la anagnórisis del desenlace sino que se extiende a lo que el protagonista comienza llamando el «mundo oscuro de la homosexualidad» (Padura, 1997: 57). Así, las duras posiciones del «machista-estalinista» que dice una y otra vez no soportar a los homosexuales (Padura, 1997: 38, 42, 58) se diluyen a través de las sucesivas conversaciones con el dramaturgo. Conde termina por comprenderlo y esa progresiva ampliación de la percepción de Conde hace ingresar toda una revisión histórica de la situación de los homosexuales en la isla. Montoya afirma que Alberto Marqués no ejerce de sospechoso sino de ayudante del policía, y su función en la novela es «convocar mediante citas, 
alusiones y referencias la historia literaria cubana reciente, en tanto a través de su presencia en el texto emergen algunos de los autores condenados al ostracismo durante la década de los setenta» (2012: 111). Además de a Virgilio Piñera, los relatos de Marqués traen a escena a un escritor homosexual silenciado en la tradición cubana a causa de su temprano exilio francés y de sus divergencias ideológicas con el gobierno. Como señala Montoya, «el Recio no es otro que Severo Sarduy (Recio/Severo), y las ideas que expone son literalmente las que este presenta en La simulación (1982), ensayo que en la novela toma el título de El rostro y la máscara» (2012: 114). En este sentido, puede decirse que la presencia de Marqués en Máscaras sirve para vehicular una crítica generacional a la política cultural cubana de los años setenta y una recuperación y revaloración de ciertos escritores que permanecieron en la sombra durante aquellos años.

Aunque sufrida en grados muy distintos, la experiencia represiva de la censura que comparten Marqués y Conde permite la identificación del policía con el dramaturgo. Ambos han pasado por lo mismo. Cuando Marqués era sentenciado a olvidarse de la gloria y los aplausos, Conde tenía dieciséis años, había escrito su primer cuento y lo habían escogido para integrar el número cero de la revista del taller literario del Pre, que al final nunca llegó a publicarse. Tanto la revista como el taller fueron clausurados bajo la acusación de que lo que allí se escribía no eran más que relatos idealistas, poemas evasivos, críticas inadmisibles; historias, en definitiva, ajenas a las necesidades actuales del país, enfrascado en la construcción de un hombre nuevo y de una sociedad nueva (Padura, 1997: 65-66). La rabia que sintió Conde en aquel momento lo capacita para imaginar lo que pudo sentir el Marqués:

¿Era tan dañino que merecía ese castigo brutal y el ejercicio castrante de la reeducación para que diez años después le dijeran que fueron errores estratégicos, malentendidos de extremistas ya sin nombre y sin buró? ¿La ideología nueva, la educación de las masas nuevas, el cerebro nuevo del hombre nuevo podían ser contaminados y hasta destruidos por empeños y ejemplos como los de Alberto Marqués? ¿O no era más perjudicial una literatura de oportunidad como la que cultivaba su excompañero Miki Cara de Jeva, siempre dispuesto a pervertir su escritura y, de paso, a vomitar su frustración sobre todo aquel que escribiera, pintara o bailara con verdadero talento? (Padura, 1997: 67) 
La rectificación que supuso el cambio en la política cultural de los ochenta en Cuba trajo consigo juicios y compensaciones para los damnificados por los procesos de parametración. A Marqués se le presentó también la oportunidad de reintegrarse en el mundo del teatro. Pero no quiso. Tampoco aceptó el salario que le ofrecieron. Las reflexiones del dramaturgo en torno a la dificultad de reparar el daño son extensibles a los casos de Piñera, Arrufat y el resto. A los «reubicados», a los silenciados, a los omitidos durante una década se les pidió entonces que olvidaran todo, que todo volviese a ser como antes. Pero Marqués no quiere olvidar y lo argumenta así: «Si no hay memoria, no hay culpa, y si no hay culpa no hace falta siguiera el perdón, ¿ve cuál es la lógica?» (Padura, 1997: 111).

Una «furtiva solidaridad de rebelde» acerca a Conde al dramaturgo a través de la experiencia compartida de la censura (Padura, 1997: 67). A medida que avanzan las conversaciones, la homosexualidad de Marqués cada vez le inquieta menos. Así lo explicita el policía: «las historias de aquel personaje que insistía en rejonearlo, rebasaban los límites de cualquier prejuicio y ya no podía verlo como el maricón de mierda con el que fue a encontrare apenas veinticuatros horas antes» (Padura, 1997: 114). Este paso del no-saber al saber en el ámbito de la subjetividad homosexual atraviesa diversas etapas hasta alcanzar un cierre cómico al final de la novela. Ocurre en su último encuentro. Conde le ha dado a leer a Marqués el cuento que ha escrito, necesita su aprobación y la encuentra, siguen conversando y en la despedida le estrecha la mano y la suelta enseguida cuando cree adivinar un acercamiento peligroso desde la cara del dramaturgo. «¿Me quiere dar un beso? No, no, ahí sí que no», pensó Conde (Padura, 1997: 230).

En este último encuentro se completa además la segunda transformación de Conde: su desenmascaramiento como escritor. Con la escena de lectura del cuento de Conde se culmina un tránsito. A lo largo de la novela, la progresiva comprensión de la subjetividad de Marqués avanza en paralelo con el deseo cada vez más agudo de Conde de regresar a la literatura. Las anécdotas, las referencias, los libros y el mismo lenguaje que trenza las conversaciones hacen que Conde evoque inevitablemente los años de su juventud, cuando soñaba con ser escritor.

El estímulo de Marqués tiene efecto. Conde termina por escribir una historia que nace de un comentario que le hizo el dramaturgo la primera vez que 
se vieron, en el umbral de su casa, cuando dijo haberlo identificado enseguida como policía por la cara (Padura, 1997: 43). Cuando Conde reconoce la idea que le hizo ponerse a escribir, Marqués se disculpa y dice que fue una broma, una defensa: «Un hombre con su sensibilidad y capaz de escribir una historia tan inquietante y tan conmovedora, pero además tan bien escrita y tan sincera, no merecía que yo lo hubiera tratado así» (Padura, 1997: 220). De esta manera, la aprobación estética del cuento por parte de Marqués marca el fin del viaje de Conde hacia la literatura. Marqués lo lee como a un escritor, no como a un policía que escribe. Lo toma en serio y los comentarios que hace a raíz de su lectura refuerzan las coincidencias experienciales y estéticas que hasta entonces solo habían asomado en los pensamientos de Conde (Padura, 1997: 219). Finalmente, cuando el dramaturgo - el silenciado político, el que parecía haber renunciado a la escritura - le enseña a Conde las ocho obras de teatro y el largo ensayo que ha ido componiendo durante los años de ostracismo, se desvela una de las tesis que circulaba implícita hasta entonces: el poder de lo imborrable, de lo eterno de la literatura frente a las circunstancias políticas coyunturales. Así debe cerrarse la representación del teatro personal de Marqués:

[M]i personaje debe sufrir silencio hasta el fin. Pero ése es el personaje: el actor ha hecho lo que debía haber, y por eso seguía escribiendo, porque, como a Milton, un día van a recordar al escritor y nadie será capaz de mencionar al triste funcionario que lo hostilizó. No me dejaron publicar ni dirigir, pero nadie me podía impedir que escribiera y que pensara. Estas dos carpetas son mi mejor venganza, ¿me entiende ahora? (Padura, 1997: 226)

\section{Mario Conde (no) soy yo: la mirada de una generación}

Leonardo Padura y Mario Conde se parecen mucho. Son varios, como veremos, los momentos en que sus biografías se entrecruzan y confunden. Pero Conde no es Padura, no es su alter ego, no es una máscara. Como explica el autor, Conde se le parece porque su intención al crearlo fue hacer de su protagonista un hombre de su generación, nacido en su mismo barrio, que hubiera estudiado en las mismas escuelas y que tuviera experiencias vitales muy semejantes a las suyas (2019: 121). La elección de un narrador equisciente para manejar esta carga sentimental y biográfica es una estrategia 
novelística muy efectiva tanto hacia dentro como hacia fuera. Hacia dentro porque humaniza al personaje y lo colma de contenido, de contradicciones, de verdad. Hacia fuera porque vehicula una mirada personal que convierte a Conde en intérprete de la misma sociedad cubana en que vive Padura, claro que con el margen, la vacilación en lo real que permite el juego de la ficción. Modificando sus palabras en la «Nota del autor» que precede a Máscaras: Mario Conde es una proyección de la vida, recuerdos, inquietudes y obsesiones de Padura en el espacio posible de la literatura.

La coincidencia biográfica entre autor y personaje más significativa en Máscaras es la experiencia de la censura. El caso de Conde se ha mencionado ya unas líneas más arriba. La experiencia personal de Padura, por su parte, es distinta solo en la superficie. Tras licenciarse en Literatura Latinoamericana, entró a formar parte de la revista cultural mensual El Caimán Barbudo, que se estaba convirtiendo en el centro activo de las preocupaciones de los jóvenes escritores de entonces y donde Padura desarrolló un fuerte sentimiento de pertenencia generacional. Escribió allí hasta que los árbitros ideológicos le pitaron falta (Padura, 2015: 13). Primero fue degradado de redactor a corrector y más tarde trasladado a un periódico diario como correctivo. Así, la disciplina y productividad obligada inherentes a este tipo de escritura no dejarían espacio para los devaneos «culturaloides» $\mathrm{o}$ «intelectualoides» que sí permitía el mensuario:

Mi falta, según los rectores de la pureza social con poder para regir sobre las personas, había sido mostrar mi inmadurez política, o sea, «tener problemas ideológicos», uno de los cargos más imprecisos pero graves que podía caer sobre alguien situado en el mundo de la cultura y el pensamiento (Padura 2019: 69).

Las razones que subyacían a este castigo son asimilables a las que adujeron los que vetaron la publicación de la revista de Conde. Según Padura, todavía en 1983 seguían funcionando algunas de las reglas del juego establecidas en los setenta (2015: 13).

Entonces yo tenía veintiocho años, era un escritor en ciernes y, como otros escritores en ciernes de mi generación, pensaba que se podía escribir literatura sobre los conflictos existenciales del hombre, sobre los eternos desafíos que enfrenta la condición humana, no solo sobre los actos heroicos 
de mis compatriotas contemporáneos o antepasados. Esos eran mis graves problemas ideológicos de aquellos tiempos. Y son algunos de los que todavía hoy me acompañan (Padura, 2019: 69).

El texto que mejor expresa los alcances de esta experiencia clave para Padura es un ensayo titulado "La generación que soñó con el futuro». En él toma sentido y anclaje histórico la percepción desencantada y el malestar que atraviesan Las cuatro estaciones. Engloba los distintos periodos vitales de la generación que había nacido en los años cincuenta, crecido en la transformadora primera década revolucionaria, que vivió su primera juventud durante los años setenta, alcanzó responsabilidad laboral en la década de los ochenta y recibió en plena madurez el duro golpe de la crisis de los noventa. Es la primera generación de la historia de Cuba que tuvo acceso masivo a los estudios superiores, la primera que creció con los planes pedagógicos soviéticos y también la primera que fue a las «escuelas de campo» donde el estudio se compatibilizaba con labores agrícolas; de esta manera, además de ayudar a la economía del país, dice Padura, «respondíamos a la puesta en práctica de la teoría del "valor formativo" del trabajo, parte esencial de la formación del Hombre Nuevo» (2019: 63). Es la generación de Máscaras. Son los que rondan entre treinta y cuarenta años en la novela, ya no son jóvenes, algunos se están quedando calvos, otros han engordado y otros han visto cómo las arrugas comienzan a poblar sus rostros (Padura, 1997: 19, 60). La escena del partido de béisbol al que intenta sin éxito sumarse el Conde es probablemente la mejor constatación narrativa de esto. El rechazo que experimenta por parte de los muchachos supone su expulsión definitiva de la juventud. Ya no pertenece a ese mundo. De esa época solo quedan las anécdotas, la evocación cíclica, la nostalgia. El primer diálogo que sostienen Conde y el Flaco Carlos en la novela apunta en esta dirección: la idealización imposible de un pasado que parece inmaculado y eterno.

Pero muchas señales visibles, y otras tantas agazapadas tras la vergüenza, el miedo, el rencor y hasta el cariño, advertían que lo único permanente era la voz grabada de Tom Foggerty y las guitarras de Credence; la calvicie amenazante del Conde y la gordura enfermiza del Flaco, que ya no era flaco; la tristeza compacta de Mario y la invalidez irreversible de Carlos eran, entre otras miles, pruebas demasiado fehacientes de un desastre lamentable y para colmo ascendente (Padura, 1997: 19). 
El personaje del Flaco Carlos es quizá el más conmovedor de la novela. Es un varado histórico; según Conde, una «víctima de una guerra geopolítica en la que fue un peón destrozado» (Padura, 1997: 233). Con esto se refiere a la participación cubana desde 1975 hasta 1991 en la guerra que Angola mantenía contra la Sudáfrica del apartheid. Según Guerra Maseda, «[e]l Gobierno y el pueblo cubano actuaron regidos por la política internacionalista de la Revolución cubana, que refrendaba una deuda histórica con el África negra, una de las raíces de la nacionalidad cubana» (2016: 500). Esta vocación internacionalista - cuyos antecedentes, en los sesenta, son las ayudas de diversa índole que Cuba prestó en Argelia, Mozambique, Guinea-Bisáu y el Congo (Guerra, 2016: 500) - es cuestionada por Padura en la novela, a través del afilado adjetivo «geopolítica», y aludida irónicamente en el ensayo:

Mi generación fue, también, la que nutrió de soldados a los ejércitos cubanos en las guerras internacionalistas de Etiopía y Angola, en las que participaron miles de jóvenes (incluso en edad de servicio militar, o sea, algo más de dieciséis años), y en las que yo mismo me vi envuelto, pues debí trabajar un año en Angola, por fortuna como corresponsal civil, por lo que merecí la distinción de Trabajador Internacionalistas que guardo en mi casa (2019: 64).

La invalidez permanente del Flaco Carlos lo convierte en recuerdo vivo de la guerra, en trauma visible en una sociedad cubana que veía regresar desde la primavera de 1989 a los combatientes que encabezaron la retirada de tropas de Angola (Guerra, 2016: 508). Para agravar la situación, la inminente vuelta a la isla del antiguo amor del Flaco Carlos hace aún más dolorosa e injusta la guerra, la bala, la silla de ruedas en que está postrado (Padura, 1997: 122).

Hacía más de diez años que Dulcita había salido para Estados Unidos, y el Conde recordó cuántas veces hablaron él y el Flaco de la partida de la muchacha que, durante dos años en el Pre, había sido la novela de Carlos. Dulcita la inteligente, Dulcita la perfecta, la buena socia, que se había ido, dejándolos con la interrogación de por qué se iba, precisamente ella. Y ahora regresaba (Padura, 1997: 123).

Dulcita ignora el estado actual del que fue su novio, por eso el deseo de verlo flota en Máscaras como una amenaza triste que intensifica la empatía del lector con el Flaco Carlos y con ella el repudio de la guerra. Por otra 
parte, la promesa del regreso de Dulcita, que no llega aparecer en Máscaras, permite traer a colación uno de los fantasmas para los cubanos que viven la isla: los cubanos que salieron de ella. Según Aja Díaz, en 1997, se estimaba en más de un millón la cifra de emigrados cubanos desde la revolución, de los cuales la mayoría recaló en Estados Unidos (2000: 1-2). Además de Dulcita, en la novela se menciona el caso de Luisito el Indio, «el único mariconcito convicto y confeso» de la generación de Conde, que vivió una historia de rechazos y abusos hasta 1980, cuando "gracias a su indiscutible condición de homosexual y, por tanto, de escoria, antisocial y excluible, se le permitió abordar tranquilamente una lancha en el puerto de Mariel y salir hacia Estados Unidos» (Padura, 1997: 75-76).

Desde su mismo título, «La generación que soñó con el futuro» plantea la tesis de que hubo una vez un horizonte de ilusión para aquellos que a principios de los ochenta oscilaban entre los veinte y treinta años. Según Padura, ese horizonte era la proyección de un futuro donde tendrían un trabajo estable y bien remunerado, podrían vivir en un apartamento propio en un barrio proletario e incluso merecer los dos grandes premios que parecía posible alcanzar en Cuba: poder adquirir un automóvil soviético y viajar al extranjero (2019: 65). Habían trabajado para ello, dice Padura, «siempre dispuestos a entregarnos, decididos a sacrificar el presente, pero sin dudas, o con muy pocas respecto al futuro que nos correspondería» (2019: 68). Pero en 1989 se produjo un punto de inflexión para ellos. El futuro soñado se truncó aquel año. A partir de 1989, todo se volvió difícil:

[M]i promoción vivió la frustración de todas las posibilidades de manosear sus manoseados y discretos sueños cuando el país cayó en la más profunda crisis económica que se pueda imaginar... Entonces, con nuestros jóvenes hijos a cuestas o nuestras esposas en la parrilla trasera, debimos empezar a pedalear sobre bicicletas chinas para llegar a cualquier sitio geográfico y garantizar la supervivencia. Al menos la supervivencia (Padura, 2019: 65).

La escasez que dominó los años del Periodo Especial exigió el esfuerzo creativo de los cubanos para sobrevivir en tan duras condiciones materiales. Como sostiene Elzbieta Sklodowska, si bien las representaciones del Periodo Especial suelen girar en torno a la carencia de alimentos y productos de primera necesidad, los cortes de luz y los problemas de transporte y de vivienda, también 
es cierto que, como contrapunto, la crisis trajo consigo el surgimiento de un imaginativo repertorio de estrategias de supervivencia, con frecuencia vinculado a chistes y comentarios satíricos e irónicos sobre la dramática situación en que vivían (2012: 224). Sklodowska se refiere aquí a lo que se conoce como el arte de «resolver» y la práctica del «invento»; según Padura, «eufemísticas denominaciones de las más diversas y enrevesadas estrategias de supervivencia, legales o ilegales» (2019: 13). Aunque la diégesis de Máscaras se limita al verano de 1989, tales estrategias ya aparecen en la novela a través del personaje de Josefina, la madre del Flaco Carlos. Sus cuidadosamente descritas recetas pueden verse como la versión cubana - con todo lo que ello implica - de las que elaboran Carvalho y Biscuter en las novelas policiales de Vázquez Montalbán. Como apunta Sklodowska, durante el Periodo Especial, las mujeres cubanas ejercerán «el papel protagónico de proveedoras de recursos materiales y espirituales necesarios para salvarse del naufragio» (2013: 101). Josefina es un ejemplo. Así describe Conde cómo es comer en su casa:

[D]ejarse sorprender era parte del rito: lo imposible se haría posible, lo soñado se transformaría en realidad, y entonces el anhelo cubano por la comida desbordaría de pronto cualquier frontera de la realidad pautada por cuotas, libretas y ausencias irremediables, gracias al acto mágico que sólo Josefina era capaz de provocar y estaba provocando (Padura, 1997: 77).

De dónde saca Josefina todo lo que pone a la mesa, es mejor no preguntarlo (Padura, 1997: 196). Se intuye así una posible ilegalidad que es palmaria en el caso del nuevo negocio que ha abierto otro de los viejos amigos de Conde. La piloto clandestina que regenta Candito el Rojo es una muestra de la economía sumergida que se extenderá durante la crisis. Otros elementos de Máscaras, como la investigación de Servicios Internos o la privilegiada situación en que vive la familia Arayán, apuntan a la corrupción y las diferencias de clase que se agudizarán tras el quiebre en la sociedad cubana que supuso el Periodo Especial.

\section{Conclusiones}

Al comienzo de este trayecto hemos examinado las coordenadas históricas y literarias en que se inscribe la novela neopolicial de Padura. A este respecto, cabe destacar la coincidencia entre el surgimiento de la novela policial 
revolucionaria y los procesos de parametración que se llevaron a cabo durante el Quinquenio Gris. Ambos fenómenos son resultado del nefasto cambio en las políticas culturales del gobierno cubano tras el Congreso de Educación y Cultura de 1971. Contra ese viraje nace Máscaras. A nivel formal, el neopolicial de Padura se opone al esquematismo maniqueo de los códigos de la novela policial revolucionaria, que no problematizaba el orden social y asumía sin reservas el discurso oficial del gobierno. Pero además la novela funciona como homenaje. A través de la figura de Marqués se canaliza una crítica generacional a la política cultural cubana de los años setenta. De esta manera, los temas y nombres a los que el dramaturgo alude a lo largo de sus conversaciones con Conde permiten insertar en la narración la denuncia de aquella exclusión injusta, la recuperación y revaloración de escritores que fueron condenados al ostracismo durante casi diez años e incluso plantear el debate acerca de la posibilidad del perdón, del olvido y de la reintegración de los damnificados.

La creación del personaje de Mario Conde a finales de 1989 le sirvió a Padura como prisma para observar y describir la realidad cubana a través de un hombre de su generación. Por eso no es de extrañar que en Máscaras puedan rastrearse los signos de lo que vendrá después. Desde ahí escribe Padura. Esta y las demás novelas de Las cuatro estaciones fueron escritas durante el brusco despertar de una generación derrotada. De aquella frustración resulta el desencanto que impregna Máscaras. La «melancolía compacta» de Mario Conde no es solo suya, ni de Padura, sino de muchos (Padura, 1997: 211). La paloma blanca que, en la última página, desafía la noche tórrida, se eleva, toma altura y cae entre piruetas hasta perderse en el vacío no solo representa a Conde, ni a Padura, sino a toda una generación.

\section{Referencias bibliográficas}

AjA DíAz, Antonio (2000), «La emigración de Cuba en los años noventa», en Cuban Studies, Vol. 30, pp. 1-25. En línea: https://www.jstor.org/stable/24487751?seq=1 Último acceso el 10-mar-2020.

EL PAís (1991), «José Abrantes Fernández, ex ministro del Interior cubano», 23 de enero de 1991. En línea: https://elpais.com/diario/1991/01/23/ agenda/664585202_850215.html Último acceso el 10-mar-2020. 
Epple, Juan Armando (1995), «Entrevista: Leonardo Padura Fuentes», en Hispamérica, $N^{o} 71$, pp. 49-66. En línea: https://www.jstor.org/stable $/ 20539850$ ?read-now $=1 \&$ refreqid=excelsior\%3A36d986d1e9715d48d2f99e2c1d1ec0da\&seq=1 Último acceso el 10-mar-2020.

ForNET, Ambrosio (2007), «El Quinquenio Gris: Revisitando el término», en Revista Criterios. En línea: http:/ / www.debatecultural.net.ve/Observatorio/FornetQuinquenioGris.pdf Último acceso el 10-mar-2020.

Franken, Clemens A. (2006), «La asimilación del género policial clásico, negro, antidetectivesco y cubano en la novela Máscaras de Leonardo Padura», en The Detective Fiction of Leonardo Padura Fuentes, ed. Carlos Uxó, Manchester Metropolitan University, pp. 114-131. En línea: https:// www.academia.edu/4257839/The_Detective_Fiction_of_Leonardo_Padura_Fuentes_edited_book_Último acceso el 4-jun-2020.

GILmAn, Claudia (2003), Entre la pluma y el fusil. Debates y dilemas del escritor revolucionario en América Latina, Buenos Aires, Siglo XXI Editores Argentina.

GuerRa MASEDA, Sandra (2016), «La participación cubana en la guerra de Angola. Cuito Cuanavale: la victoria sobre la Sudáfrica del apartheid», en Transiciones en el mundo contemporáneo, coord. por Alberto Reig Tapia y Josep Sánchez Cervelló, pp. 497-510. En línea: http:/ /libres.urv.cat/index. php/purv/catalog/view/191/173/424-1 Último acceso el 10-mar-2020.

Mesa-Lago, Carmelo (2005), «Problemas sociales y económicos en Cuba durante la crisis y la recuperación», en Revista de la CEPAL, 86, pp. 184205. En línea: https://www.cepal.org/es/publicaciones/11076-problemas-sociales-economicos-cuba-durante-la-crisis-la-recuperacion Último acceso el 10-mar-2020.

Montoya, Oscar E. (2012), «Leonardo Padura Fuentes: Las máscaras sexuales y estéticas de la revolución», en Hispanic Review, Vol. 80, No. 1, pp. 107-125. En línea: https://www.jstor.org/stable/41472648?seq=1\#metadata_info_tab_contents Último acceso el 10-mar-2020.

Padura, Leonardo (1997), Máscaras, Barcelona, Tusquets Editores.

- (1999) «Modernidad y posmodernidad: La novela policial en Iberoamérica», en Hispamérica, No. 84, pp. 37-50. En línea: https:/ / www.jstor.org/ stable/20540154?read-now=1\&seq=1 Último acceso el 10-mar-2020. 
- (2015) Yo quisiera ser Paul Auster: ensayos selectos, Madrid, Editorial Verbum.

- (2019) Agua por todas partes, Barcelona, Tusquets Editores.

Piglia, Ricardo (2001), Crítica y Ficción, Barcelona, Anagrama.

PONCE, Néstor (2010), «Leonardo Padura. Les territoires de la fiction dans la révolution cubaine», en Amerika. Disponible en: http:/ /journals.openedition.org/amerika/568 Último acceso el 10-mar-2020.

QueSADA, Uriel (2016), «Saldar cuentas con la historia: las cuatro estaciones, de Leonardo Padura», en Diálogos, Vol. 20, No. 1, pp. 2-7. En línea: https:/ / www. redalyc.org/pdf/3055/305546699002.pdf Último acceso el 7-mar-2020.

Redruello, Laura (2010), «"El lobo, el bosque y el hombre nuevo": un final para tres décadas de dogmatismo soviético", en Chasqui: revista de literatura latinoamericana, Vol. 39, No. 1, pp. 120-129. En línea: https://search. proquest.com/openview/8f1780f59f9308e602d56ac4863edfac/1?pq-origsite=gscholar\&cbl=27737 Último acceso el 8-mar-2019.

Rosell, Sara (2000), «La (re)formulación del policial cubano: la tetralogía de LeonardoPaduraFuentes», en Hispanic Journal,Vol.21,No.2, pp.447-458. En línea: https:/ / www.jstor.org/stable/44284644?read-now=1\&seq=5\#page_scan_tab_contents Último acceso el 10-mar-2020.

SÁnchez Zapatero, Javier y Martín Escribì, Àlex (2014), «Revolución, desencanto y crítica: la novela criminal cubana», en Cuadernos de Investigación Filológica, No. 40, pp. 171-189. En línea: https:/ / publicaciones.unirioja.es/ ojs/index.php/cif/article/view/2663/2486 Último acceso el 4-jun-2020.

SkLodowsKa, Elzbieta (2013), «Invento, luego resisto: El Período Especial en Cuba a través de la lente de género», en Cuadernos de Literatura del Caribe e Hispanoamérica, No. 18, pp. 81-103. En línea: http://investigaciones. uniatlantico.edu.co/revistas/index.php/cuadernos_literatura/article/ view/1206 Último acceso el 10-mar-2020.

- (2012) «Reinventando la rueda: El Período Especial en el imaginario cubano», en Itinerarios, Vol. 16, pp. 221-235. En línea: https://dialnet.unirioja. es/servlet/articulo?codigo=5996170 Último acceso el 10-mar-2020. 
WiLKINSON, Stephen (2006), "Critiques of sexual and political intolerance in Leonardo Padura's novel Máscaras and the film Fresa y chocolate», en The Detective Fiction of Leonardo Padura Fuentes, ed. Carlos Uxó, Manchester Metropolitan University, pp. 132-159. En línea: https://www.academia. edu/4257839/The_Detective_Fiction_of_Leonardo_Padura_Fuentes_ edited_book_Último acceso el 4-jun-2020. 


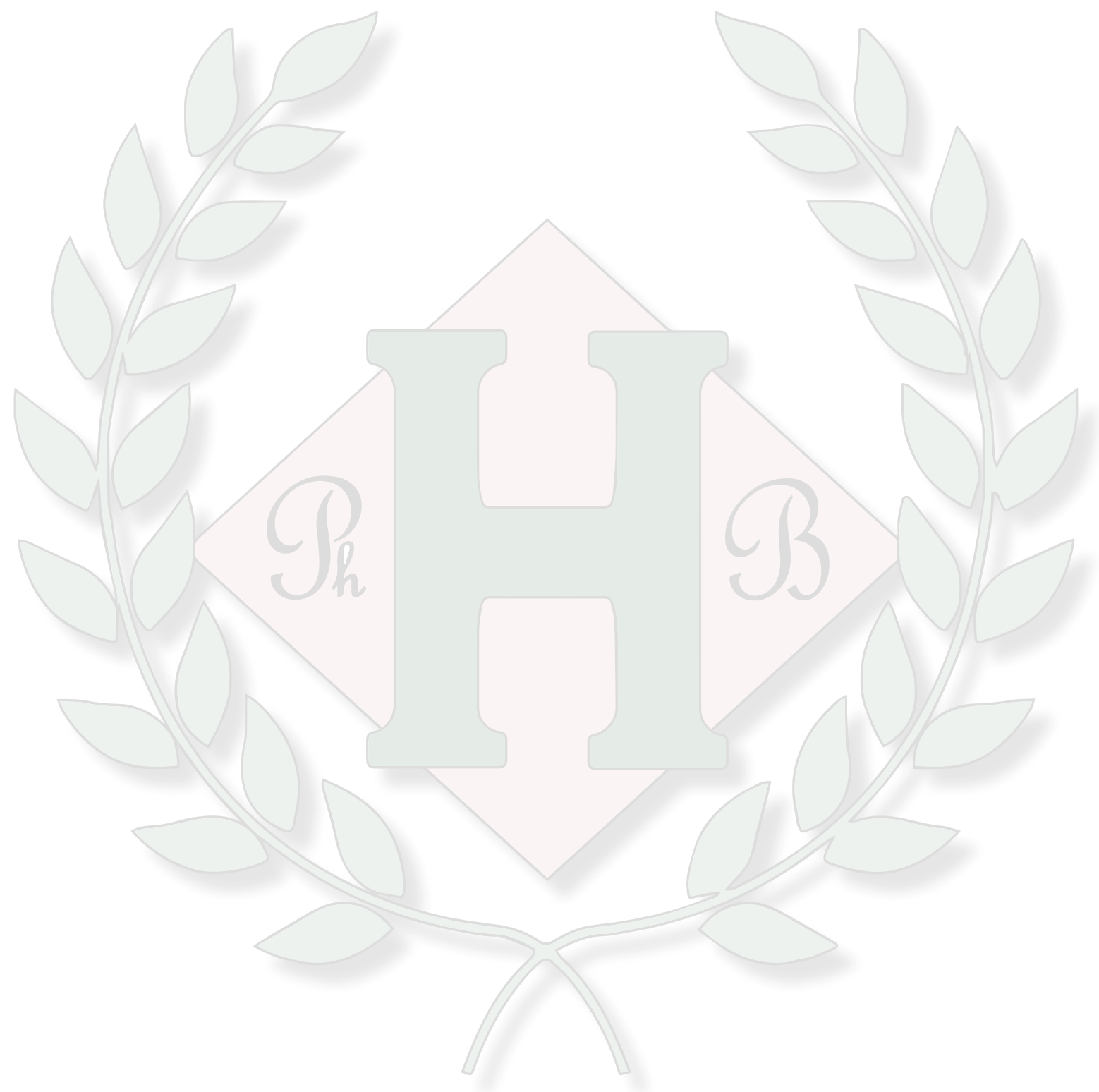

